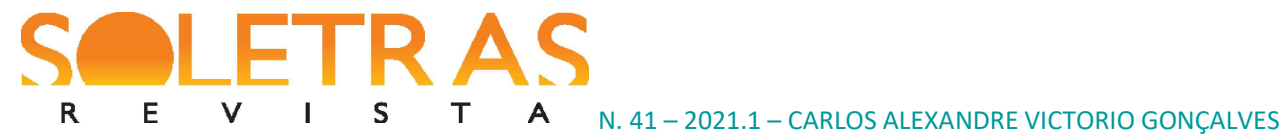

\title{
Algumas notas sobre Morfologia Relacional: uma "prima" da Gramática das Construções
}

\author{
Carlos Alexandre Victorio Gonçalves ${ }^{1}$
}

\begin{abstract}
Resumo: No presente artigo, pretendemos apresentar um recente quadro teórico surgido no âmbito da Gramática das Construções: a Morfologia Relacional. Desenvolvida nos quatro últimos anos por Ray Jackendoff (USA) e Jenny Audring (Holanda), o modelo inova não apenas ao priorizar a morfologia, como o faz a Morfologia Construcional de Booij (2010), mas também por enfatizar as relações horizontais entre esquemas, generalização que os autores denominam de "esquemas irmãos". Procuramos mostrar suas vantagens no tratamento de questões morfológicas, como os hápax sufixais e os padrões "virais", muito embora o modelo também aborde questões sintáticas. Ao apresentar esse novo quadro teórico, procuramos mostrar os pontos de convergência e de divergência entre este e outras abordagens construcionistas.
\end{abstract}

Palavras-chave: Morfologia Relacional. Gramática de Construções. Morfologia Construcional. Esquemas Morfológicos.

\section{Para início de conversa}

Neste texto, temos o propósito de apresentar as principais ideias de um modelo extremamente recente para o tratamento de questões morfológicas, a Morfologia Relacional (JACKENDOFF \& AUDRING, 2016). Apesar de o modelo ir além da morfologia, sendo igualmente operante no nível da sintaxe (cf. JACKENDOFF \& AUDRING, 2020), limitarnos-emos, aqui, a observar as vantagens desse quadro teórico na descrição de problemas clássicos de morfologia, tentando, na medida do possível, aplicá-lo ao português.

Em primeiro lugar, procuramos mostrar em que medida a Morfologia Relacional (MR) dialoga com outros modelos construcionistas, que Jackendoff \& Audring chamam de "primos", sobretudo com a proposta de Booij, a Morfologia Construcional (MC), cujo parentesco é ainda mais próximo. Uma das proponentes do modelo, Jenny Audring, trabalha na mesma instituição de Booij, a Universidade de Leiden, na Holanda, e escreveu com ele

\footnotetext{
${ }^{1}$ Doutor em Linguística (UFRJ). Pós-doutoramento em interface morfologia-fonologia (UNICAMP, 2001) e em interface morfologia-semântica (UERJ, 2017). Líder do NEMP (Núcleo de Estudos Morfológicos do Português), desde 2003, e Professor Titular da UFRJ, desde 2016. Rio de Janeiro, Brasil. E-mail: carlexandre@bol.com.br. ORCID iD: 0000-0003-3672-3852
} 


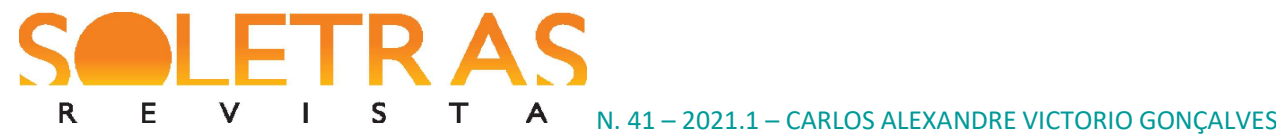

vários artigos (cf., p ex., BOOIJ \& AUDRING, 2017), o que nos leva à ousadia de afirmar que MR e MC são “irmãs”, usando uma terminologia muito cara ao primeiro modelo.

$\mathrm{Na}$ sequência, observamos as principais diferenças entre a MR e os demais modelos construcionistas, tentando, com isso, advogar sobre as vantagens dessa abordagem. Nessa empreitada, tratamos de temas como os seguintes: (a) os pluralia tantum, (b) casos de hápax sufixais, (c) raízes de fronteira e (d) padrões virais, sobretudo os relacionados ao splinter bolso-, oriundo do sobrenome do atual chefe do executivo. Obviamente, deixaremos de abordar muitas outras questões caras ao modelo, como as declinações e as vogais temáticas, bem como os elementos de ligação (vogais e consoantes). Nosso objetivo principal, portanto, é apresentar o modelo e trazer alguma aplicação para o português.

\section{Morfologia construcional: ideias básicas e vínculo com a Gramática das Construções}

Entre os diversos modelos de Gramática de Construções (GC) existentes (cf., p. ex., GOLDBERG, 1995; CROFT \& CRUISE, 2001), um deles foi desenvolvido especificamente para o tratamento de fenômenos morfológicos, ainda que, teoricamente, as abordagens construcionistas se proponham a dar conta da língua em todos os seus níveis, ao conceberem um continuum do léxico para a sintaxe. A Morfologia Construcional, criada pelo holandês Geert Booij em seu trabalho pioneiro de 2005, comprova que flexão, derivação e composição, principais áreas da morfologia, podem ser descritas por padrões idênticos ao de construções sintáticas, que variam em tamanho, esquematicidade e complexidade. Igualmente bebe de várias fontes da Linguística Cognitiva para descrever o polo semântico das formações lexicais (cf., p. ex., FILLMORE, 1982). Portanto, apesar de os estudos em GC já terem grande acolhida no tratamento de fenômenos sintáticos e semânticos, sua efetiva aplicação à morfologia foi tardia: demorou pelo menos 20 anos, considerando como marco os trabalhos seminais da década de 1980 (cf. SALOMÃO, 2009).

Uma construção morfológica pode ser concebida como um pareamento convencionalizado de forma e sentido (BOOIJ, 2010), assim como as construções sintáticas. De acordo com Hoffmann \& Trousdale (2013, p. 1), a igualdade das definições tem uma importante implicação teórica: "uma vez que o conhecimento linguístico humano é 


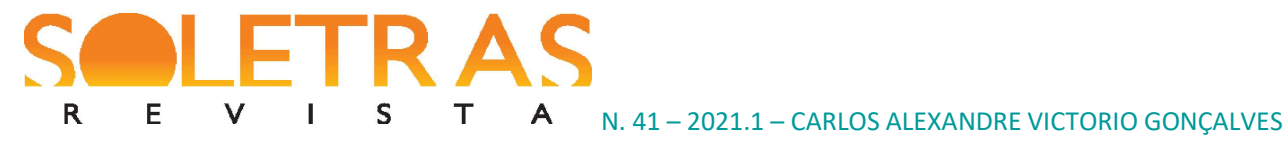

armazenado em um constructicon, isto é, em uma rede de construções, tanto material sintático quanto material morfológico fazem parte do mesmo domínio construcional”. Sem dúvida alguma, há uma sintonia direta entre o modelo de Booij, que culminou na publicação de seu livro pela Oxford em 2010 (BOOIJ, 2010), as Gramáticas de Construções (o plural é intencional) e todo o arcabouço que vem sendo desenvolvido, inclusive no Brasil, na linha da Linguística Funcional Centrada no Uso (cf., p. ex., TRAUGOTT \& TROUSDALE, 2013).

Ao se expressar como um linguista construcionista, Basilio (2010, p. 20), que vem repensando muitos dos seus estudos na linha gerativa, ressalta que "deixa de ser crucial a questão de determinar, por exemplo, se um composto é ou não uma palavra; ou se uma construção é composta ou prefixada". Mais ainda, reforça a ideia de que palavras (primitivas e derivadas) "são unidades simbólicas complexas convencionais, cujas propriedades comuns podem ser representadas em esquemas construcionais, desde os mais especificados, como $\left[[\text { Xizar }]_{V} \text {-ção }\right]_{\mathrm{N}}$ até os mais abstratos como [N-N $]_{\mathrm{N}}$ " (BASILIO, 2010, p. 21).

Gonçalves \& Almeida (2012, 2014, 2016) vêm demonstrando que as unidades linguísticas são estruturas simbólicas convencionais. Por isso mesmo, não há diferença significativa entre formas flexionadas ('gat-a'), prefixações ('anti-bolsonarismo'), derivações ('fasc-ista'), compostos neoclássicos ('xeno-fobia'), compostos lexicais ('cheque-família'), expressões parcialmente especificadas ('pé-de-X') e idiomatismos ('bater com a cara na porta'): "todas essas unidades, que são complexas, podem, igualmente, ser analisadas, em suas estruturas de formação, por meio de esquemas construcionais" (GONÇALVES; ALMEIDA, 2012, p. 110). A representação a seguir, extraída de Croft (2007, p. 468), ilustra bem o pareamento do polo semântico com o formal na Gramática das Construções (GC), perspectiva teórica em que a Morfologia Construcional se inscreve explicitamente: 


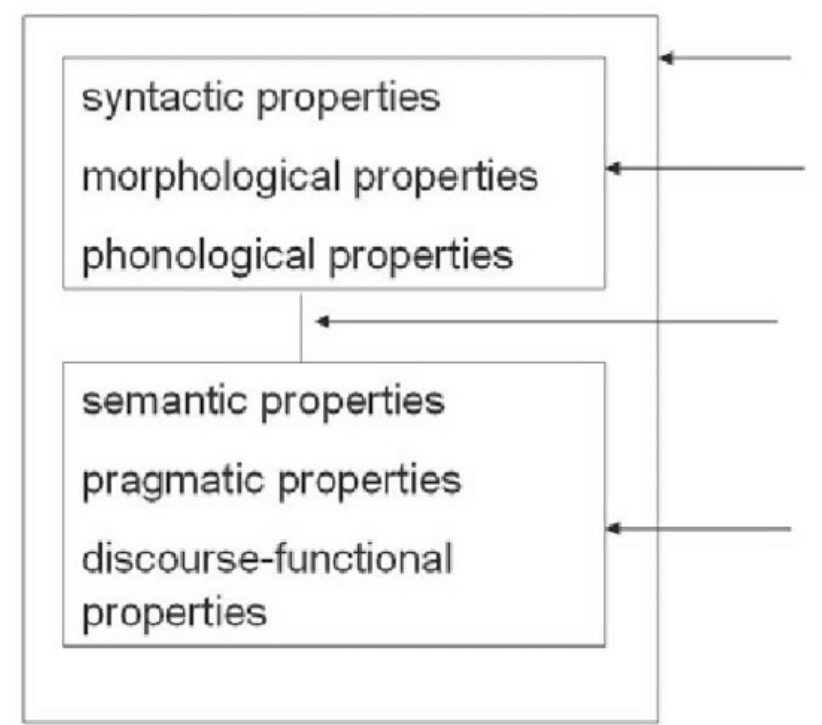

CONSTRUCTION

FORM

Symbolic

correspondence (link)

(CONVENTIONAL)

MEANING

Figura 1: Pareamento forma-significado na Gramática das Construções

A título de exemplificação, tomemos por base o conjunto de dados abaixo, que deve ser lido em duas colunas. São casos de compostos de base verbal que, obviamente, formam substantivos, uma vez que essa é a função principal do processo de composição (cf., p. ex., SCALISE et al., 2009):

$\begin{array}{ll}\text { (01) engasga-gato } & \text { porta-copos } \\ \text { papa-moscas } & \text { porta-talher } \\ \text { baba-ovo } & \text { porta-chaves } \\ \text { puxa-saco } & \text { porta-papel }\end{array}$

Todos os casos de (01) são instâncias de um processo de composição cuja representação mais abstrata aparece na primeira linha da representação em (02), a seguir. Além de serem compostos, os itens lexicais em (01) também compartilham a estrutura: o primeiro elemento é uma base verbal e o segundo, um substantivo. Teríamos, nesses casos, quase uma relação do tipo verbo-objeto direto, embora a função de denominação por metonímia suplante a ideia de que temos aí "uma estrutura sintática com fins lexicais" (BASILIO, 1987, p. 48). Temos, portanto, dois níveis necessários, como representado em (02):

(02) Esquema da composição: Esquema dos compostos verbais: $\quad\left[[\mathrm{X}]_{\mathrm{v}}[\mathrm{Y}]_{\mathrm{s}}\right]_{\mathrm{S}}$ 
Nesses esquemas, as variáveis $\mathrm{X}$ e $\mathrm{Y}$ representam sequências fonológicas e os subscritos x e y, categorias lexicais. O esquema geral dos compostos, na primeira linha, expressa a generalização de que a composição, independentemente da etiquetagem lexical de seus constituintes, sempre forma nomes (substantivos ou adjetivos) em português (daí o rótulo N, após o último colchete). No polo do significado, Booij (2010) propõe a semântica de "Y com alguma relação com X", numa clara tentativa de "puxar o significado para cima" (SOARES DA SILVA, 2006). Na segunda linha, temos a especificação dos subscritos, pois as unidades envolvidas são $\mathrm{V}$ (verbo) e $\mathrm{S}$ (substantivo). O produto é sempre um substantivo. Uma especificação semântica do tipo "ALGO(UÉM) XY (METAFÓRICA E/OU METONIMICAMENTE)" garante a $\mathrm{SEM}^{2}$ genérica do esquema.

A descrição dos dados em (01), no entanto, não para por aí. Há um conjunto de formas que apresentam um elemento fixo na primeira posição e podemos captar essa generalização admitindo, aqui, um esquema mais especificado que o da segunda linha de (02):

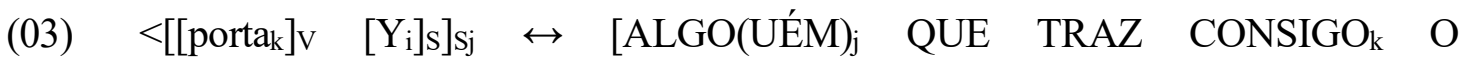 REFERENTE $\left._{\mathrm{i}}\right]_{\mathrm{S} j}>$}

Nesse esquema, temos o pareamento forma/significado do esquema porta-X. Na formalização, os símbolos maior que e menor que (respectivamente, $<,>$ ) demarcam o esquema e a seta de mão dupla $(\leftrightarrow)$ relaciona forma e significado no interior do esquema. Os subscritos $\mathrm{k}$, i e j informam que essas formas fazem parte do léxico, tendo todas etiquetas categoriais $(\mathrm{V}, \mathrm{S})$. Somente a forma fonológica de Y não é especificada. De acordo com Booij (2010, p. 35),

\footnotetext{
${ }^{2}$ SEM abrevia SEMântica e deve ser interpretado como o frame ativado pela cena. Entendemos, com Fillmore \& Atkins (1992, p. 76), que "palavras e significados de palavras não são relacionados uns aos outros diretamente, palavra a palavra, mas somente por meio das associações aos frames de base compartilhados e das indicações da maneira pela qual seus significados destacam elementos específicos de tais frames". Além disso, as construções linguísticas se alternam segundo os ajustes focais que os falantes realizam em relação a uma dada cena. Tais ajustes, segundo Langacker (1987: 117), são organizados pela seleção, determinante da faceta de uma cena pela qual o falante irá optar; pela perspectivação, relacionada à posição em que a cena está sendo observada; e, por fim, pela abstratização, referente ao nível de especificidade em que a cena é retratada. O ajuste focal é feito em função do significado da base em relação ao do afixo.
} 


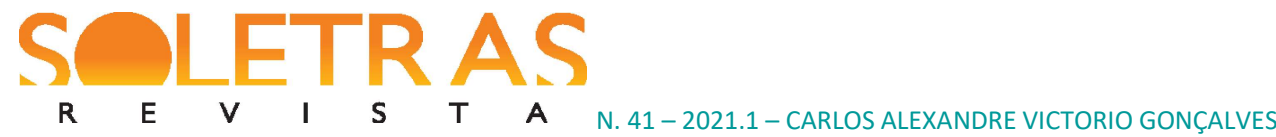

uma hierarquia organizada em esquemas e subesquemas funciona como uma descrição sincrônica para padrões e possibilidade de formação de novas palavras de diferentes subtipos. Isso significa que pode revelar como os mecanismos de extensão conceptual são convencionalizados em uma língua particular.

A representação a seguir, cujo mecanismo envolvido é sempre a herança ${ }^{3}$, permite relacionar os vários níveis de especificidade das construções porta-X. Como se observa, as palavras complexas ('porta-níquel', 'porta-papel' etc.) constituem o último nó da rede, pois são as instâncias específicas dos esquemas.
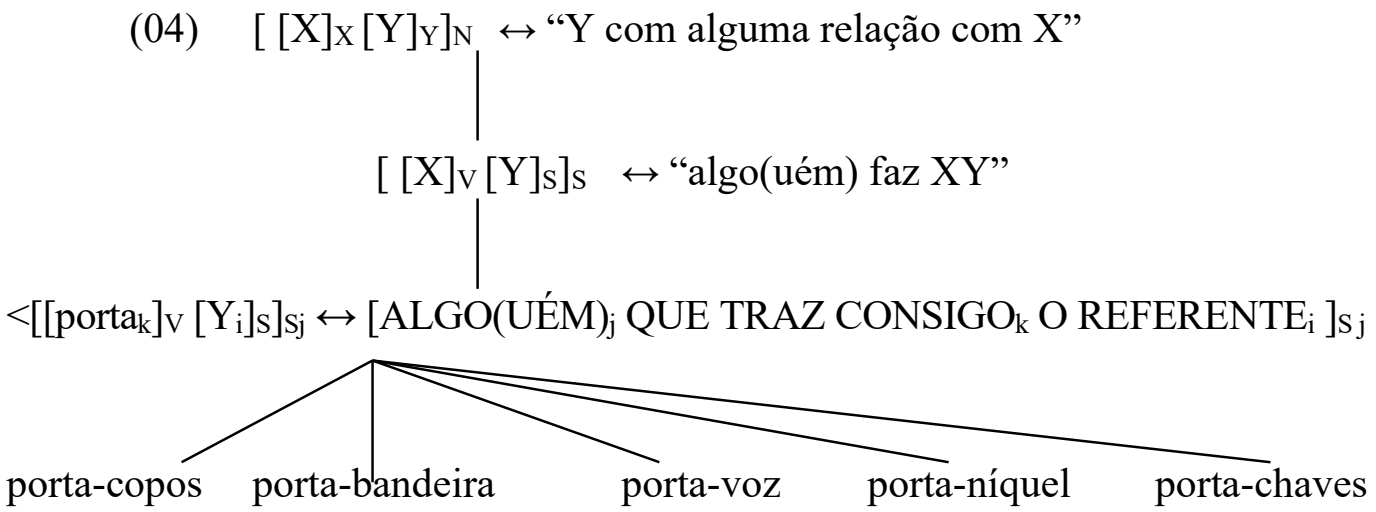

Como bem observa Barbosa (2020), há uma clara relação entre o modelo de Booij e o de outros teóricos. Desse modo, os diferentes níveis hierárquicos de esquematicidade

recebem denominações diversas, de acordo com a LFCU. De modo geral, os autores concebem três níveis hierárquicos de esquematização. Traugott (2008) e Trousdale $(2008 ; 2010)$ denominam os níveis de macroconstrução, mesoconstrução e microconstrução; mais tarde, ambos, em parceria (TRAUGOTT \& TROUSDALE, 2013), mudam sua taxonomia para esquema, subesquema e microconstrução; já Booij adota os termos esquema geral, esquema dominante, subesquema. Do mesmo modo, distintos processos

\footnotetext{
${ }^{3} \mathrm{O}$ conceito de rede construcional - e suas relações - consiste, nesse sentido, essencialmente, na ideia de que tudo na língua pode ser descrito em termos de nós e tipos de relação/herança entre níveis mais altos e menos específicos e níveis mais baixos e mais especificados que herdam propriedades dos mais altos.
} 
morfológicos de formação de palavras, como derivação e composição, são operados por esquemas construcionais situados no constructicon. (BARBOSA, 2020, p. 97)

Passemos, agora, à apreciação de um parente próximo da GC, que Jackendoff \& Audring (2016) chamam de "prima": a Morfologia Relacional. Brincando com essa relação de parentesco, que está no cerne do próprio modelo, ousamos afirmar que a Morfologia Construcional constitui "irmã” da Relacional, uma vez que Geert Booij é parceiro tanto de Ray Jackendoff quanto de Jenny Audring em vários trabalhos, incluindo um escrito pelos três: Audring, Booij \& Jackendoff (2018).

\section{Primeiras notas sobre a Morfologia Relacional}

O objetivo básico da Morfologia Relacional (MC) é “a integração harmoniosa da morfologia com o resto da linguagem e com o resto da mente" ${ }^{4}$ (JACKENDOFF \& AUDRING, 2020, p. 480). Por isso mesmo, a MR leva muito a sério o termo conhecimento da linguagem, focalizando a questão do que um falante armazena na memória de longo prazo e, principalmente, de que maneira. Harmonizando-se explicitamente com a Gramática das construções (GC), reunimos, a seguir, dez assunções que a MR compartilha com as abordagens construcionistas:

a) a faculdade da linguagem é uma habilidade cognitiva humana, que utiliza o mesmo aparato de outras tarefas (CROFT; CRUSE, 2004). Dito de outra maneira, há processos cognitivos envolvidos na interação linguística, e tais processos utilizados para a linguagem não são muito diferentes daqueles usados para outras tarefas cognitivas, tais como a percepção visual, o raciocínio ou a atividade motora; desse modo,

b) conhecimento linguístico é conhecimento (GOLDBERG, 2006);

\footnotetext{
${ }^{4}$ Todas as traduções feitas do inglês são livres e de nossa responsabilidade. 
c) “a linguagem é a percepção e produção em tempo real de uma sequência temporal de unidades discretas, estruturadas e simbólicas. Essa configuração particular das habilidades cognitivas é provavelmente única à linguagem, mas as habilidades cognitivas requeridas não o são" (CROFT; CRUSE, 2004, p. 2);

d) o conhecimento da língua emerge do uso e nisso a Gramática das Construções deve se alinhar com os modelos baseados no uso (GOLDBERG, 2006);

e) as representações sintática, morfológica e fonológica são basicamente conceptuais, e, embora sons, e até os enunciados, sejam entidades físicas, eles precisam ser compreendidos e produzidos através de processos mentais;

f) a unidade fundamental da gramática é o pareamento forma-significado, chamado de construção (ou esquema, no nosso caso), o que acarreta que regras gramaticais estão no mesmo formato básico que palavras: são relações estruturadas de forma e significado; por isso mesmo,

g) não há distinção entre léxico e a gramática, pois tanto as palavras quanto as regras são tratadas como itens em um "léxico estendido" ou "constructicon" (JACKENDOFF \& AUDRING, 2018);

h) Construções mais centrais (core Grammar) e as mais periféricas devem receber o mesmo tratamento, vinculando-se por relações de herança: não é adequado descrever construções de uma língua com base em seu grau de convencionalização (GOLDBERG, 2006);

i) A aquisição da linguagem é baseada em itens: "as gramáticas não geram sentenças; são os falantes que o fazem" (GOLDBERG, 2006, p. 22); “as línguas são aprendidas, ou seja, são construídas com base em input junto com restrições cognitivas e pragmáticas genéricas" (GOLDBERG, 2006, p. 2). Por isso mesmo,

j) Crianças aprendem padrões de uso, e sua competência linguística se define como o domínio de um inventário estruturado de unidades simbólicas.

Acrescentaríamos, também, parafraseando Goldberg (2006, p. 22), que, na MR, as gramáticas não geram palavras; são os falantes que o fazem. Por outro lado, também existem diferenças entre a MR e os vários modelos construcionistas existentes, incluindo o de Booij. Por exemplo, nessas abordagens, uma construção é definida como um signo 


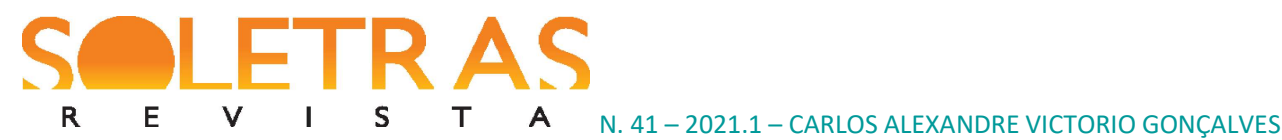

linguístico, ou seja, como um pareamento entre forma (fonologia, sintaxe) e um significado (função), como na Figura 1, mais acima.

Em consonância com essas análises, a MR assume essa relação, mas também admite a possibilidade de esquemas / construções que não envolvam semântica, como, por exemplo, padrões fonotáticos, elementos morfológicos sem sentido, como marcadores de palavras, vogais temáticas e elementos relacionais que funcionam como "cola" morfológica, a exemplo das vogais e consoantes de ligação. Consequentemente, a MR interpreta "as construções que relacionam forma e função como apenas um subconjunto do conhecimento total da linguagem de um falante" (JACKENDOFF \& AUDRING, 2020, p. 480).

Uma segunda diferença entre a MR e a MC diz respeito ao repertório de relações entre itens lexicais. Destacamos, mais acima, que o principal tipo de relação lexical é a herança, "uma relação entre uma palavra ou construção e outra construção mais abstrata, de forma que esta última motive parcialmente a estrutura da primeira" (JACKENDOFF, AUDRING, 2018, p. 432). A MR admite tais relações, mas, além disso, permite relações "horizontais", diretas ou "irmãs", entre palavras ou entre esquemas, "para as quais, em muitos casos, não é atraente postular uma "mãe" abstrata que captura o que elas têm em comum" (JACKENDOFF, AUDRING, 2018, p. 433). No seu texto de (2019), que traduzimos como "Mães ou irmãs? A codificação do conhecimento morfológico", para dar ao leitor uma ideia do modelo, Jenny Audring assim se expressa sobre as relações entre construções:

Enquanto as abordagens tradicionais vêem a gramática como um sistema de regras, as teorias baseadas em construção assumem esquemas declarativos entradas lexicais com variáveis - como o locus do conhecimento gramatical. Esses esquemas são evidentemente necessários para codificar padrões produtivos. No entanto, o conhecimento morfológico também inclui relações entre palavras existentes, em padrões que não podem necessariamente ser estendidos produtivamente (...). Tais padrões podem ser codificados de duas maneiras: por um esquema "mãe" dominando as instâncias listadas, ou por ligações "irmãs" entre as próprias instâncias. Os links irmãos são a opção mais parcimoniosa, uma vez que não requerem uma camada superordenada na rede construtiva. No entanto, os esquemas mãe podem codificar propriedades que os links irmãos não podem (AUDRING, 2019, p. 277). 


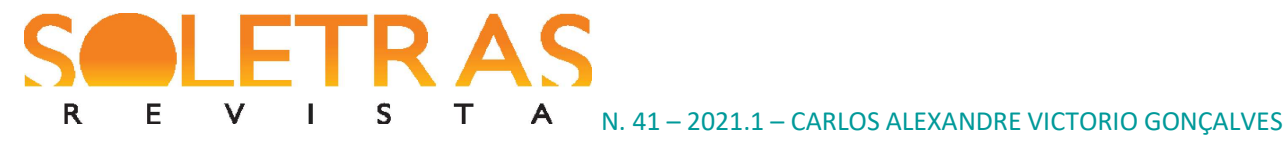

Uma terceira diferença entre os modelos está no formalismo, sobre o qual falaremos na próxima seção. Ambas, MR e MC, adotam o termo "esquema" em lugar de "construção", mas a MR enfatiza a distinção entre fonologia, sintaxe, morfossintaxe e semântica no âmbito dos esquemas como meio de distinguir os padrões produtivos dos não produtivos.

Uma última diferença, que Jackendoff \& Audring (2016, 2018, 2020) chamam de "ponto final mais filosófico", está no fato de a MR admitir a possibilidade de princípios de linguagem específicos de cada nível de descrição da estrutura linguística, enquanto os modelos de construção, em sua maioria, tendem a ver a linguagem inteiramente como um subproduto de processos cognitivos mais gerais. Enfatizam os autores, no entanto, que a MR "está, obviamente, comprometida em minimizar os aspectos específicos de cada domínio da linguagem" (JACKENDOFF \& AUDRING, 2016, 477), mas não supõe que sejam completamente inexistentes.

\section{O formalismo da MR e sua aplicação a fenômenos morfológicos}

Uma questão que imediatamente se coloca em relação ao formalismo é a utilização de esquemas. Os autores defendem que há uma diferença significativa no uso de esquemas no lugar de regras: "esquemas têm o mesmo formato que palavras, diferindo apenas na parte de sua estrutura que consiste em variáveis e variáveis coíndices" (JACKENDOFF \& AUDRING, 2016, 485). Na citação a seguir, os autores fornecem uma explicação que sustenta melhor esse raciocínio:

em praticamente todas as teorias linguísticas, uma palavra contém peças de estrutura em três níveis: sua estrutura semântica, suas características sintáticas e sua fonologia. No paradigma da Arquitetura Paralela, esses níveis são, em princípio, independentes, cada um com suas próprias condições de boa formação características. No entanto, cada um também está ligado aos outros: a camada fonológica pode ser ligada à sintaxe e à semântica. Chamamos esses links de interface de conexões, e os notamos com índices que mostram quais partes da estrutura em um nível correspondem à estrutura em outro nível. [...] Os índices devem ser pensados como marcando o fim das linhas de associação (JACKENDOFF \& AUDRING, 2016, 487). 
Tomemos como exemplo uma construção atômica como 'boi'. Essa palavra não complexa consiste em um pedaço de estrutura semântica (o significado da palavra), grafado em maiúsculas, BOI, um pedaço de estrutura fonológica (/ 'boj /) e a categoria sintática Substantivo (S). Na representação a seguir, o agrupamento desses componentes em uma unidade lexical é notado convencionalmente por uma relação por um cossubscrito convencional, como ${ }_{1}$. Os subscritos podem ser considerados marcando o que os autores chamam de links de interface.

$\begin{array}{ll}\text { SEMÂNTICA: } & {\left[\mathrm{BOI}_{1}\right]} \\ \text { MORFOSSINTAXE: } & \mathrm{S}_{1} \\ \text { FONOLOGIA } & / \text { 'boj }_{1} /\end{array}$

Considerando, por exemplo, o plural em português, uma abordagem serialista formularia uma regra do tipo "adicione $-s$ ao final de um nome (S ou Adj) para expressar a noção de mais de um”. A contrapartida na MR é a formulação de um esquema como em (06), a seguir, em que a primeira linha poderia ser interpretada, nos modelos construcionistas, como a construção de plural em português:

$\begin{array}{ll}\text { SEMÂNTICA: } & {\left[\left(\mathrm{X}_{\mathrm{X}}\right) \text { PLUR }\right] \mathrm{Y}} \\ \text { MORFOSSINTAXE: } & {\left[\mathrm{N}_{\mathrm{X}} \mathrm{PLUR}_{2}\right] \mathrm{Y}} \\ \text { FONOLOGIA } & / \ldots \mathrm{X} \mathrm{S}_{2} / \mathrm{Y}\end{array}$

Da mesma maneira que a palavra em (05), o esquema em (06) consiste em um pedaço de semântica, um pedaço de morfossintaxe e um pedaço de fonologia; os três estão ligados por subscritos. Nas palavras de Jackendoff \& Audring (2018, p. 134), (06) difere de (05) “porque partes de sua estrutura são variáveis: ela diz que uma multiplicidade (PLUR) de qualquer tipo de entidade $(\mathrm{X})$ pode ser expressa por um nome $(\mathrm{N})$ mais um afixo plural ( PLUR ); na fonologia, a combinação é pronunciada seguida pelo fonema / s /".

A forma de plural 'bois' pode ser produzida instanciando as variáveis em (05) com as peças correspondentes de (06), resultando na estrutura (07). O esquema em (07) pode ser instanciado de forma semelhante com substantivos recém-encontrados para produzir espontaneamente novas expressões, a exemplo das formas emprestadas do inglês 'nerds' e 'tweets'. 


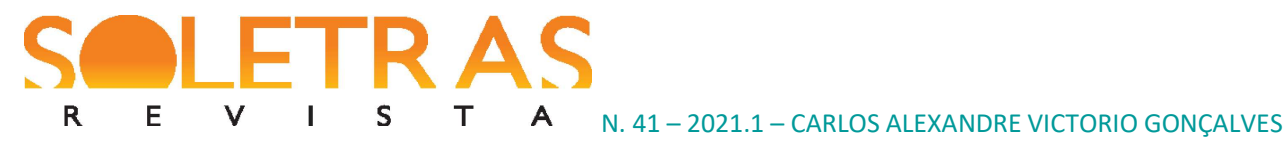

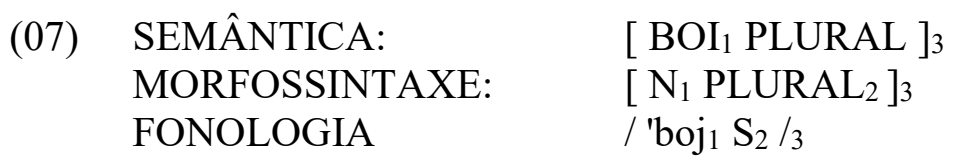

Por outro lado, também dá conta dos chamados pluralia tantum, expressão latina com que são referidos os substantivos de uma língua cuja forma é um plural morfológico, mas que semanticamente podem denotar uma única unidade, como em (08), a seguir:

$\begin{array}{lllll}\text { (08) pêsames } & \text { núpcias } & \text { bodas } & \text { exéquias } \\ \text { férias } & \text { parabéns } & \text { anais } & \text { víveres } \\ \text { primícias } & \text { fezes } & \text { confins } & \text { condolências }\end{array}$

Para dar conta dos dados em (08), basta não linkar os nós MORFOSSINTAXE e FONOLOGIA ao nó SEMÂNTICA, generalizando que as formas em (08) apresentam um -s ao final da palavra e são plurais porque ativam o mecanismo da concordância (lembremos que o modelo admite esquemas sem contraparte semântica). Muito embora as bases possam não ser reconhecidas, ainda assim, estaria preservada, nos termos de Bybee (2010), a analisabilidade $^{5}$ das formações, ainda que a interpretação não seja necessariamente composicional. No nosso entendimento, há perda da analisabilidade nos pluralia tantum que deixam de requerer concordância, como é, o caso, por exemplo, de 'óculos', que hoje parece estar no conjunto de formas anoxítonas terminadas em -s ('lápis', 'ônibus') com marcação de plural na sintaxe: "lindo óculos" (singular), “dois óculos" (plural).

$$
\begin{array}{ll}
\text { MORFOSSINTAXE: } & {\left[\ldots 1 \mathrm{PLURAL}_{2}\right]_{3}} \\
\text { FONOLOGIA } & / \ldots 1 \mathrm{~S}_{2} / 3
\end{array}
$$

Jackendoff \& Audring (2016) argumentam que existem esquemas com funções gerativas e relacionais. No entanto, não há esquemas com função apenas gerativa, "porque qualquer instância de um esquema que pode ser gerada online pode também ser armazenada [...] Pode-se armazenar itens de todos os tamanhos [...] sem perder a estrutura interna que os conecta aos padrões gramaticais da língua” (JACKENDOFF \& AUDRING, 2016, p. 473).

\footnotetext{
${ }^{5}$ Bybee (2010) distingue composicionalidade de analisabilidade. Embora reconheça que essas duas propriedades sejam estreitamente relacionadas e gradientes, ela prefere distingui-las para efeitos de análise da variação das expressões linguísticas. Enquanto a composicionalidade é associada à atribuição do significado do todo com base no significado das partes de uma expressão composta, a analisabilidade se relaciona ao grau em que os falantes reconhecem, e tratam distintamente, essas partes componentes.
} 
Portanto, existem dois tipos de esquemas: os produtivos e os não produtivos. Os primeiros desempenham a função de regras gerativas tradicionais e apreendem generalizações em itens lexicais, enquanto os últimos abrangem apenas a função relacional. Os autores afirmam que o conhecimento da linguagem é uma rede que possui nós interligados. Quando se considera a relação entre palavras em redes lexicais, não necessariamente se admite que haja ligação simples entre os nós; ao contrário, os nós contêm estruturas internas que são conectadas por links relacionais. Portanto, para explicar a função relacional, primeiro temos que suplementar os links de interface com um segundo tipo de links: os relacionais.

Consideremos, para tanto, a palavra 'bebum'. A sequência -um se comporta como um sufixo deverbal adjungido à raiz beb-. No entanto, esse "afixo" é exclusivo de tal palavra, não havendo nenhuma outra na língua que apresente tal forma nessa posição. Muito apropriadamente, Jackendoff \& Audring (2018) mostram que seria totalmente contraproducente formular uma regra de formação de palavras como "acrescente -um ao final de uma base verbal para expressar a intensificação de um atributo", pois, afinal de contas, uma regra que se aplica a uma só palavra não é propriamente uma regra. No entanto, a relação entre 'beber' e 'bebum' pode ser capturada na notação MR, conforme mostrado em (10):

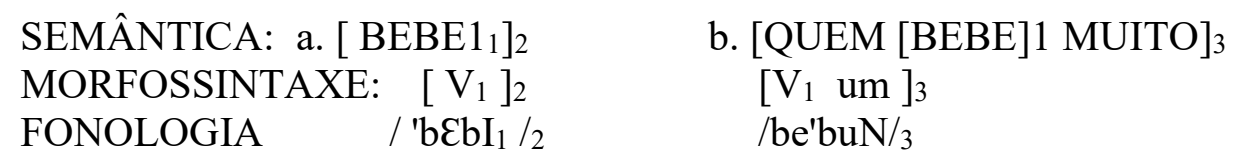

b. [QUEM [BEBE]1 MUITO] 3

$\left[\mathrm{V}_{1} \text { um }\right]_{3}$

$/ \mathrm{be}$ buN $/ 3$

O subscrito 1 liga os três níveis de 'beber' e, da mesma forma, o subscrito 3 liga os três níveis de 'bebum'. Por outro lado, o subscrito 1 também liga 'bebum' à base de 'beber', marcando os dois como iguais. Essa conexão é o que Jackendoff \& Audring (2016, 2018, 2020) chamam de link relacional. Este link não é usado para derivar 'bebum' de 'beber'; em vez disso, simplesmente marca o que os dois itens lexicais compartilham. O vínculo (marcado pelo coíndice), portanto, “apoia” ou "motiva" 'bebum': torna-o menos arbitrário do que uma palavra importada como 'crush', que carece de estrutura interna. 'Bebum' é mais fácil de aprender, então, porque tem uma parte previamente conhecida; e é mais fácil de processar, por causa da ativação extra que vem de 'beber' e de outros derivados, como, por exemplo, 'bêbado', 'bebida', 'beberagem', 'beberrão' e 'bebeção'. Ao contrário do que possa parecer, esses casos, que Gonçalves (2016) vem chamando de hápax sufixais, são mais abundantes que 


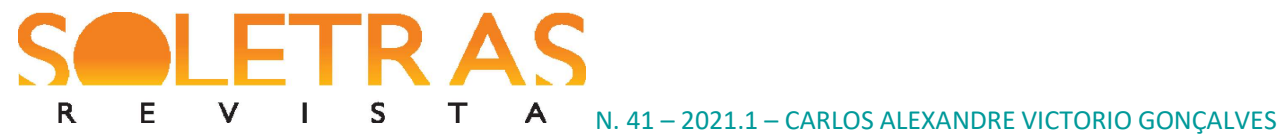

parecem. Uma análise dos hápax à luz da Morfologia Relacional é encontrada em Gonçalves et al. (no prelo).

Voltando à função relacional dos esquemas, vemos, nos idiomatismos em (11), que os significados dessas expressões não podem ser construídos a partir dos significados de suas partes e, por isso mesmo, tais expressões devem ser aprendidas e armazenadas.

(11) Dar com os burros n'água.

Soltar os cachorros.

Matar dois coelhos com uma cajadada

Pôr o carro na frente dos bois.
Ter costas quentes.

Colocar os pontos nos "is".

Ter duas caras.

Meus sentimentos.

Como enfatizamos ao longo desta seção, a Morfologia Relacional generaliza padrões entre palavras em um léxico e os representa como esquemas. Embora o significado das expressões em (11) não seja composicional, nada impede que sejam armazenadas como unidades holísticas não estruturadas: sem dúvida alguma dialogam com o esquema-irmão de plural em (07). Como ressaltam Jackendoff \& Audring (2018, p. 338),

Em particular, os substantivos no plural ainda são substantivos no plural padrão, embora não sejam gerados espontaneamente. A Morfologia Relacional captura essa generalização estabelecendo links relacionais entre o esquema de plural e os plurais idiomáticos armazenados. Nesse caso, a conexão não é entre subscritos compartilhados, mas sim entre subscritos de variáveis no esquema e subscritos constantes em suas instâncias. Novamente, a intuição é que o vínculo relacional com o esquema torna essas expressões mais fáceis de aprender e processar.

$\mathrm{Na} \mathrm{MR}$, ao contrário de outras abordagens construcionistas, reforçamos, os esquemas têm dois usos: o gerativo e o relacional. Muitos deles, no entanto, podem desempenhar apenas a função relacional. Bom exemplo em português é a pequena família de adjetivos terminados em -onho. Como se vê em (12), há claramente um padrão: três substantivos e um adjetivo são acrescidos desse "sufixo" e formam um adjetivo cujo significado é "que desperta, causa ou aparenta $X^{\prime \prime}$. 
(12) riso - risonho

medo - medonho

enfado - enfadonho

triste - tristonho

Obviamente, podemos formular um esquema para dar conta dessas formas em português. Esse esquema, no entanto, está longe de ter função gerativa, pois os falantes do português não formam, nos dias de hoje, adjetivos com essa terminação, soando estranhas palavras como ?choronho, ?raivonho ou ?contentonho, todas com bases compatíveis com o significado do afixo. O esquema em (13), portanto, tem função apenas relacional, já que serve para conectar esse pequeno conjunto de palavras complexas.

(13) SEMÂNTICA:

[QUE DESPERTA, CAUSA OU APARENTA $]_{1}$

MORFOSSINTAXE: $\quad\left[\mathrm{N}_{2} \text { onho }\right]_{1 \text { Adj }}$

FONOLOGIA $\quad / \ldots 2$ õnU/1Adj

Concluindo brevemente a respeito dos padrões derivacionais gerais, na terminologia de Basilio (1980), esquemas irmãos estão "onipresentes em fenômenos morfológicos como relações paradigmáticas, categorias flexionais, alomorfia de radical, reduplicação e truncamento sistemático" (JACKENDOFF \& AUDRING, 2018, p. 335). No livro de 2020, essas são as questões centrais de três capítulos (JACKENDOFF E AUDRING, 2020b, capítulos 4-6). Afirmam os autores que "o tratamento de esquemas irmãos é uma simples extensão formal de palavras irmãs" (JACKENDOFF \& AUDRING, 2018, p. 336), o que constitui outra razão para eliminar a distinção entre o léxico e a gramática. Por isso mesmo, a noção de esquemas irmãos, para os autores, "não está disponível nem nas regras tradicionais de formação de palavras, nem na noção padrão de herança" (JACKENDOFF \& AUDRING, 2018, p. 337). O caso a seguir ilustra bem o poder descritivo da MR.

Além de todos os casos de relações irmãs já apresentados, podemos citar exemplos como 'emoção' e 'emotivo'. Esse par compartilha uma base lexical que não se atualiza como palavra e, por isso mesmo, não pode ser etiquetada. A análise relacional constitui alternativa interessante. Considere-se o seguinte esquema:

(14) a

SEMÂNTICA:

MORFOSSINTAXE:

\section{[ ATO DE EMOCIONAR ]1}

[...2 Af3 ]S1 


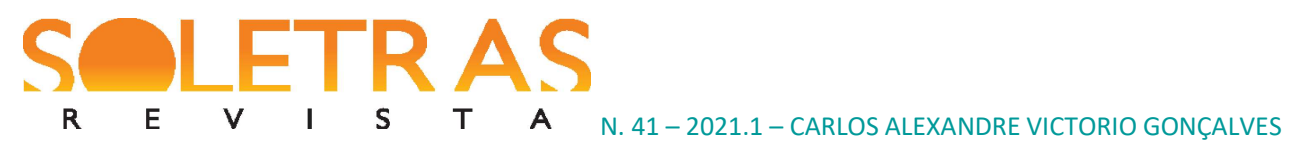

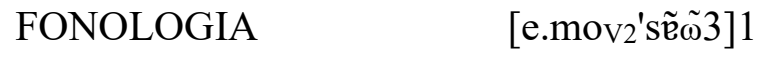

b.

$\begin{array}{ll}\text { SEMÂNTICA: } & \text { [ QUE SE EMOCIONA ]4 } \\ \text { MORFOSSINTAXE: } & {[\ldots 2 \text { Af5]N4 }} \\ \text { FONOLOGIA } & {[\text { e.mov''tivu5]4 }}\end{array}$

Pares como 'emoção'/'emotivo' estão longe de ser isolados na língua e tampouco se resumem a esses sufixos; são mais numerosos do que se pensa, como bem observado em Basilio, na tese pioneira de 1979, publicada em 1980, hoje um clássico em morfologia (BASILIO, 1980). No léxico do português, formas relacionadas sem raiz com livre curso aparecem em palavras como 'interior'-'posterior'-'ulterior', 'polonês-'polaco'-'Polônia' e por que não estender? - no recente par 'sanduíche'-'sanduba', para citar apenas alguns.). Os proponentes do modelo assim se expressam a respeito de duplas de palavras como essas:

Um tratamento tradicional dessas palavras em termos de regras de formação de palavras teria que capturar a relação entre elas, postulando uma forma abstrata [...] da qual as duas palavras seriam derivadas. Esta forma teria de estipular de alguma maneira que só pode ser pronunciada se derivada [...], uma solução altamente artificial (JACKENDOFF \& AUDRING, 2018, p. $340)$.

Também haveria a possibilidade de se propor que 'emotivo' é derivado de 'emoção' por meio do apagamento de -ção e do posterior acréscimo de -tivo, através de um mecanismo que ficou conhecido na perspectiva gerativa como regra de truncamento (ARONOFF, 1977). Da mesma maneira, uma abordagem em termos de herança exigiria uma construção abstrata que contribuísse com a forma fonológica / emo /, o polo formal, e COMOVER, o polo semântico, mas, com isso, deixa os afixos em aberto, o que, nas palavras de Jackendoff \& Audring (2018, p. 337), “mais uma vez não é uma solução ideal”. Para eles, “a relação irmã no formalismo [...] novamente diz exatamente o que precisa ser dito".

Em resumo, esquemas são expressos nos mesmos termos que palavras, a saber, como peças de estrutura linguística - semântica, (morfo)sintaxe e fonologia - conectadas por links de interface quando apropriado. Diferem das palavras porque têm variáveis que devem ser 


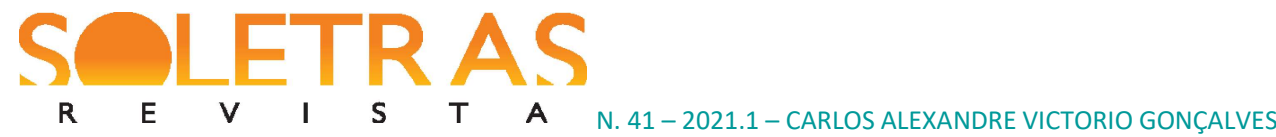

instanciadas na construção de um enunciado. As relações entre as palavras armazenadas são expressas por links relacionais, que marcam partes idênticas de itens relacionados. Os links relacionais também conectam esquemas a suas instâncias armazenadas. Ao reformular essas ideias, os autores concluem que todos os esquemas podem funcionar de forma relacional, enquanto apenas alguns podem funcionar gerativamente. Pode-se pensar nos últimos, então, como esquemas que, por assim dizer, "se tornaram virais".

A seguir, mostramos a análise de um esquema viral à luz da MR: as formações com o splinter bolso- a partir do sobrenome do atual presidente. Na próxima seção, confrontaremos a MR com a MC na análise das formações lexicais com base no splinter bolso-, que, aproveitando as palavras finais do parágrafo precedente, tornaram-se virais. A análise pela MC foi feita em Gonçalves (2020), texto do qual extraímos os dados aqui utilizados. No referido artigo, todas as formações estão devidamente referenciadas pelas fontes de que foram rastreadas.

\section{Padrões "virais": um contraponto entre a MR e a MC}

Desde o período eleitoral de 2018, muitas construções lexicais foram criadas envolvendo o nome e o sobrenome do atual presidente, Jair Messias Bolsonaro (GONÇALVES, 2020): (a) cruzamentos vocabulares ('Mijair', 'Boltergeist', 'coronaro'), (b) decomposições sublexicais ('Bolso cheio', 'Já ir se acostumando', 'Me chias') e (c) formações com splinters iniciais ('bolso-afetivo', 'bolso-torturador') e finais ('hittlernaro', 'chatonaro'), além de (d) criações analógicas ('bozonero', 'biroliro'). Nesta parte do trabalho, tomamos por base apenas as formações iniciadas por bolso-.

Desde Bauer (2004), splinters vêm sendo considerados "pedaços de palavras utilizados com fins lexicais e geralmente resultam de processos de fusão vocabular" (GONÇALVES, 2011, p. 12). Dito de outra maneira, são "elementos que, como os afixos, ocorrem numa borda específica da palavra, mas, em função de seus significados, correspondem a lexemas. Splinters, portanto, formam uma classe à parte, situada entre radicais e afixos" (GONÇALVES, 2013, p 190). Novidade no estudo dos splinters, apontada 


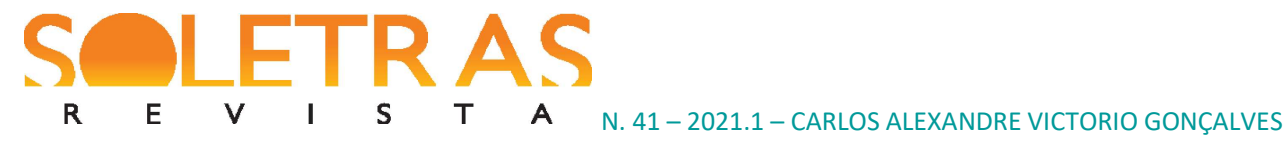

em Benfica da Silva (2019), é a possibilidade de nomes próprios também poderem ser fontes de criação dessas unidades. Consideremos as formas em (15), a seguir:

\section{A}

Bolsonazi

Bolsoneca

Bolsonicho

Bolsonojo

Bolsonagem

Bolsonada

Bolsonabo

Bolsotário

Bolsospício

Boçalnaro

Bozonaro

Bobonaro

Bestanaro

\section{B}

Bolsoanta

Bolsoasno

Bolsobosta

Bolsoburro

Bolsodemo

Bolsofake

Bolsofilho

Bolsohitler

Bolsolábia

Bolsolixo

Bolsolaia

Bolsomerda

Bolsomito
C

Bolsoditador

Bolsotorturador

Bolsokid

Bolsovampiro

Bolsolunático

Bolsominion

Bolsoquadrilha

Bolsoréu

Bolsotroglodita

Bolsofascista

Bolsoviolência

Bolsoladrão

Bolsocaixa 2

Se, por um lado, as formas do grupo A e do grupo B possam ser consideradas cruzamentos vocabulares, respectivamente, por entranhamento lexical (por compartilharem material fonológico) e por combinação truncada (por preservarem a métrica da maior base e mais segmentos da menor), o mesmo não pode ser dito em relação às construções do grupo $\mathrm{C}$. No nosso entendimento, é bem melhor unificar os grupos e assumir que a sequência bolsoadquiriu estatuto próprio e, de tão viralizada, passou a criar séries de palavras. Formações como as em (15) apresentam um elemento recorrente à esquerda, "o que, de certo modo, thes dá o direito de reivindicar (a) a existência de concatenação e (b) um estatuto morfológico próprio" (GONÇALVES, 2013, p. 196).

Na formalização a seguir, também típica da abordagem construcional de Booij (2010), as letras i e j, subscritas, indicam que base e produto fazem parte do léxico, por serem interpretáveis na forma resultante. Lembramos que SEM é interpretado como o frame evocado pela palavra-fonte, pois somente desse modo podemos entender que, com base no mesmo esquema, formam-se construções com semânticas distintas: 
(16) $<\left[\right.$ BOLSO $\left._{\mathrm{i}} \mathrm{X}_{\mathrm{N}}\right] \mathrm{S}_{\mathrm{j}} \leftrightarrow\left[\mathrm{SEM} \mathrm{DEX}\left(\text { ou parte de X) envolvida na } \mathrm{SEM}_{\mathrm{i}}\right]_{\mathrm{j}}>\right.$

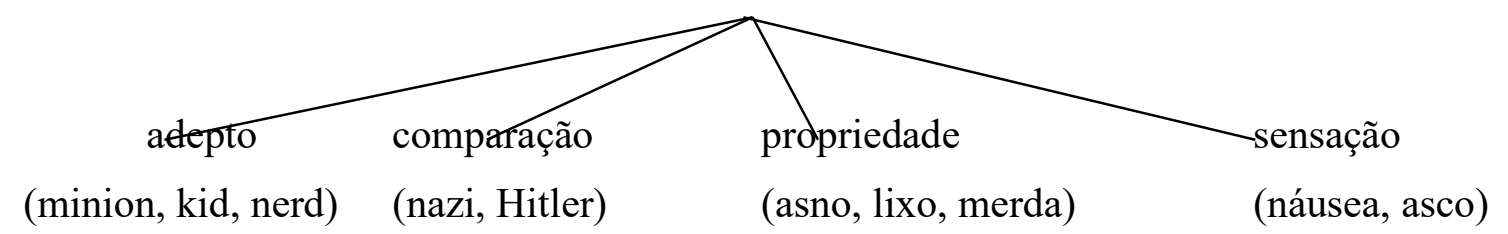

Sem dúvida alguma, (15) pressupõe o encurtamento da forma de base 'Bolsonaro', o que, no modelo de Booij (2010), constitui herança por subparte, já que Bolso- compacta o significado da palavra-matriz e leva esse significado para as novas construções. Ao instanciar novas unidades a formação bolso- se enquadra no esquema da prefixação, pois, nesse caso, $Y$ tem de ser categorialmente etiquetado e responde pela classe do produto (na prefixação base e produto são da mesma classe):

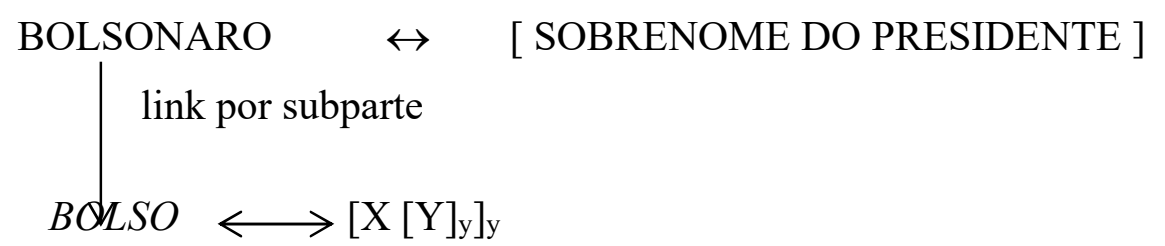

Dessa maneira, bolso- aponta para a figura presidente, mas agora como uma forma diminuta, presa, com o formato morfoprosódico próprio de um splinter: um pé troqueu silábico (ANDRADE, 2013), representado por (* .), em que a cabeça figura à esquerda (é um dissílabo paroxítono), comportando-se exatamente como as seguintes unidades:

$\begin{array}{ll}\text { caipi- } & \text {-nese } \\ \text { choco- } & \text {-nejo } \\ \text { piri- } & \text {-guete } \\ \text { ciber- } & \text {-drasta } \\ \text { info- } & \text {-gate }\end{array}$

Nesse ponto da análise, caberia indagar quais seriam as vantagens de uma análise relacional para as formas bolso-X, uma vez que é satisfatória a descrição pela Morfologia Construcional. Ao separar, num esquema, as dimensões semântica, morfossintática e fonológica, é possível especificar a pronúncia das instanciações. Com isso, as formações com splinters diferem das criações analógicas que "veem", na sequência inicial, um substantivo próprio que remete, por exemplo, a um lugar em que se guarda dinheiro: 'bolso'. 


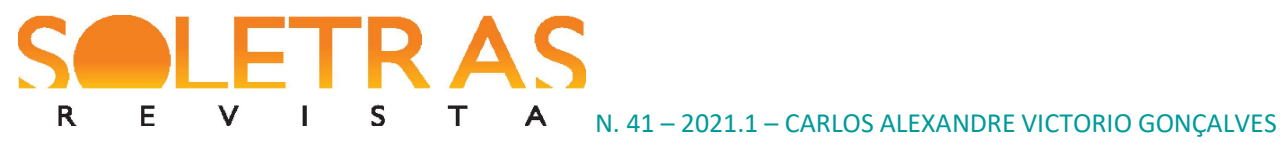

Confrontando-se (19a) com (19b), observa-se que, apesar de existirem duas palavras prosódicas em ambos os casos, somente nos dados da segunda coluna ocorre o fenômeno da neutralização das postônicas, fazendo com que a vogal final do substantivo neoanalisado seja realizada como alta, $[v]^{6}$ :

(19) bolso-afetivo

[o]

bolso-nabo

[o]

bolso-lão

[o] bolso cheio

[v]

bolso farto

[U]

bolso endinheirado

[v]

Os dados de (19) revelam que não se criou um homônimo, uma vez que a forma presa só compartilha com a livre a grafia, mas não a pronúncia. Isso é capturado na MR pela especificação do nó FONOLOGIA. No entanto, acreditamos, a principal vantagem do modelo vem a ser a identificação desse [o] como marcador de palavra, pois essa vogal é, em essência, marca específica da composição neoclássica (cf. HIGINO DA SILVA, 2016), como em 'soci[o]pata' e 'ort[o]rexia', além de compostos coordenativos ('lingu[o]dental', 'álve[o]palatal') e recompostos ('ec[o]via', 'aer[o]lula'), o que pode ser identificado através da postulação de construções-irmãs, como se formaliza em (20):

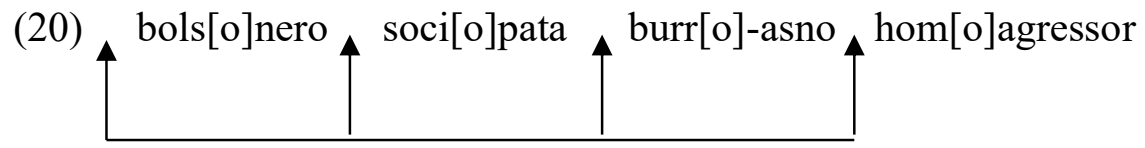

Todas essas formações se distanciam dos compostos com bases livres, todos eles com cabeça à esquerda ('bomba-relógio', 'tubarão-martelo') e sem qualquer marca morfológica que os identifique. As formas em (20) ou são copulativas ('burro-asno') ou têm cabeça à esquerda, o que as torna, no nosso entendimento, não marcadas.

\footnotetext{
${ }^{6}$ Num teste informal com cinco informantes, pedimos que os consultores lessem 10 formações com o bolsosplinter e 10 com o 'bolso' em neoanálise. As formas foram pronunciadas com [o] e [ひ], respectivamente, em quase cem pontos das realizações obtidas, o que confirmou a intuição do pesquisador.
} 


\section{É tempo de concluir}

A MR, como enfatizamos, foi proposta justamente para acolher o que há de mais morfológico ("morphologic by itself", parafraseando um famoso livro de Mark Aronoff, ou "morfologia pura"): classes formais, declinações, elementos de fronteira etc. Mesmo admitindo que há um continuum do léxico para a sintaxe, a MR considera as especificidades da morfologia e consegue acolher as relações entre palavras e esquemas não apenas verticalmente (pelo mecanismo de herança), mas também horizontalmente (instâncias irmãs).

Procuramos, neste texto, fornecer ao leitor uma pequena amostra da Morfologia Relacional, modelo extremamente recente no cenário das Linguística Cognitiva, em geral, e da Gramática das Construções, mais particularmente. Ao exemplificar o quadro teórico com dados do português, quisemos mostrar as vantagens desse "filho mais novo", para não escapar à terminologia adotada. Obviamente, o modelo, por ser extremamente recente, não escapa a críticas ou a pontos que carecem de maior reflexão e/ou aprofundamento. Um deles, sem dúvida, é a questão histórica. A própria Jenny Audring, em entrevista a Gonçalves, Soledade \& Simões Neto (no prelo) reconhece isso:

“Entrevistadores: As propostas de descrição morfológica das línguas, de maneira geral, se voltam, em um primeiro momento, ao enquadramento sincrônico dos fenômenos morfológicos e, só depois, são vistas abordagens diacrônicas. Para a Morfologia Relacional, o estudo diacrônico da morfologia é um desafio? Como a historicidade das línguas é trabalhada nesse modelo?

Jenny Audring: Nosso trabalho, tenho que admitir, confirma o padrão que você descreve: começamos na ponta sincrônica e ainda não descobrimos como os dados históricos podem ser utilizados no modelo (e vice-versa). Teríamos o prazer de convidar outros pesquisadores a expandir a pesquisa nessa direção". 


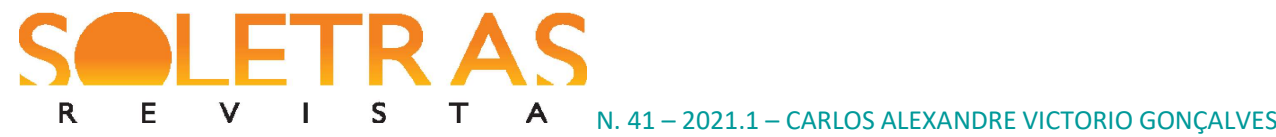

\section{Referências}

ANDRADE, K. E. Proposta de um continuum composição-derivação para o Português do Brasil. Tese de Doutorado. - Rio de Janeiro, UFRJ, 2013.

AUDRING Jenny. Mothers Or Sisters? The Encoding Of Morphological Knowledge. Word Structure 12(3): 274-296, 2019.

; BOOIJ Geert; Jackendoff, Ray. Menscheln, kibbelen, sparkle: Verbal diminutives between grammar and lexicon. In Sander Lestrade \& Bert le Bruyn (eds.) Linguistics in the Netherlands. Amsterdam: Benjamins., 2017.

BARBOSA, Luiz Pedro da Silva. Forma verborvm: abordagem construcional dos sufixos pré-desinenciais de verbos latinos. Tese (Doutorado em Estudos Linguísticos). Niterói: UFF, 2020.

BASILIO, Margarida. Abordagem gerativa e abordagem cognitiva na formação de palavras: considerações preliminares. LinguíStica (Rio de Janeiro), v. 6, p. 11-26, 2010.

. Teoria Lexical. São Paulo: Ática, 1987.

Estruturas lexicais do português. Petrópolis: Vozes, 1980.

BAUER, L. Glossary of morphology. Edinburgh: Edinburgh University Press, 2004.

BENFICA da SILVA, Vitória. O cruzamento vocabular formado por antropônimos: análise morfológica e fonológica. Dissertação (Mestrado em Letras Vernáculas) - Faculdade de Letras, Universidade Federal do Rio de Janeiro. Rio de Janeiro: UFRJ, 2019.

BOOIJ, Geert. Construction Morphology. In: HIPPISLEY, A.; STUMP, G. T. (eds.). The Cambridge Handbook of Morphology. Cambridge: Cambridge University Press, 2015.

. Construction morphology. Oxford: Oxford University Press, 2010.

Construction morphology and the lexicon. In: MONTERMINI, F.; BOYÉ, G.; HATHOUT, N. (eds.). Selected proceedings of the 5th Décembrettes: Morphology in Toulouse. Somerville: Cascadilla Press, pp. 34-44, 2007.

Compounding and Derivation. Evidence for Construction Morphology. In: W. DRESSLER et al. (eds.). Morphology and its Demarcations. Amsterdam / Philadelphia: John Benjamins Publishing Company, pp. 109-131, 2005.

. Morphology in construction grammar. In: HOFFMANN, T. and TROUSDALE, G. (org.). The Oxford Handbook of Construction Grammar. Oxford: Oxford University Press, p. 255-273, 2013. 
; AUDRING, Jenny. Construction Morphology And The Parallel Architecture Of Grammar, Cognitive Science 41 (S2): 277-302, 2017.

; AUDRING, Jenny. Category change in Construction Morphology. In Evie Coussé,

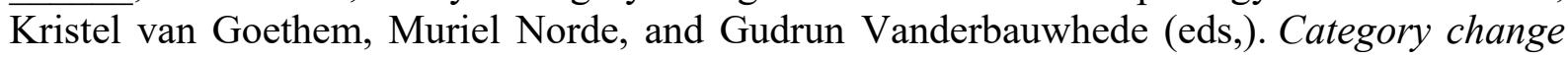
from a constructional perspective. Amsterdam / Philadelphia: Benjamins, 209-228, 2017.

BYBEE, Joan. Language, usage, and cognition. Cambridge, UK: CUP, 2010.

CROFT, William. Radical Construction grammar: syntactic theory in typological perspective. Oxford: Oxford University Press, 2001.

. Construction Grammar. In: D. Geeraerts / H. Cuyekens (Eds). The Oxford Handbook of Cognitive Linguistics. Oxford / New York, Oxford University Press, 2007, p. 463-508.

.; CRUSE, D. A. Cognitive linguistics. New York: Cambridge University Press, 2004.

FILLMORE, Charles. Frame semantics. In: ---. Linguistics in the Morning Calm. Seul: Hanshin Publishing Co., p.111-137, 1982.

\& ATKINS, B. Toward a frame-based lexicon: the semantics of RISK and its neighbors. In: LEHRER, A. \& KITTAY, E. Frames, fields and contrasts. Hillsdale, N. J.: Lawrence Erlbaum, 1992.

GOLDBERG, Adele. Constructions at work. The nature of generalization in language. Oxford: Oxford University Press, 2006.

. Constructions: a construction grammar approach to argument structure. Chicago; London: The University of Chicago Press, 1995.

GONÇALVES, Carlos Alexandre. Uma análise construcional das (de)formações lexicais com os nomes do atual chefe do executivo. Gragoatá, Niterói, v.25, n. 52, p. 648-687, mai.-ago., 2020.

. Morfologia. São Paulo: Parábola, 2019.

. Atuais tendências em formação de palavras. São Paulo: Contexto, 2016.

. Na sextaneja com a caipifruta da mãedrasta: o estatuto morfológico dos splinters no português brasileiro contemporâneo. Diadorim, Rio de Janeiro, v. esp., n. 13, p. 139-158, 2013.

. Composição e derivação: polos prototípicos de um continuum? Pequeno estudo de casos. Domínios de Lingu@gem, 5, p.62-89, nov. 2011.

; ALMEIDA, Maria Lucia Leitão. Morfologia construcional: o que é e como se faz. In: GONÇALVES, Carlos Alexandre. Introdução à morfologia construcional: São Paulo: Contexto. 


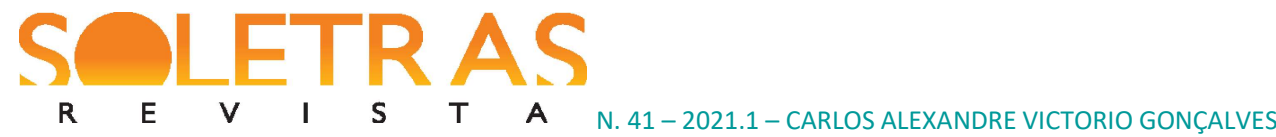

; SOLEDADE, Juliana; SIMÕES NETO, Natival (no prelo). Livro inédito organizado pelos autores a ser publicado pela EDUFBA em 2021.

; ALMEIDA, Maria Lucia Leitão. Morfologia construcional: principais ideias, aplicação ao português e extensões necessárias. Alfa (ILCSE/UNESP), v. 58, n. 1: 165-193 2014.

; ALMEIDA, Maria Lucia Leitão. Por uma Cibermofologia: Abordagem Morfossemântica dos Xenoconstituintes em Português. In MOLLICA, M. C. \& GONZALEZ, M. (orgs.). Linguística e Ciência da Informação: Diálogos Possíveis. Curitiba: Appris, p. 105-127, 2012.

HOFFMAN, T., \& TROUSDALE, G. (Eds.). The Oxford handbook of Construction Grammar. Oxford: Oxford University Press, 2013.

LANGACKER, R. Foundations of cognitive grammar: Theoretical Prerequisites. Stanford, CA: Stanford University Press, 1987.

JACKENDOFF, Ray; AUDRING, Jenny. The Texture of the Lexicon. Relational Morphology and the Parallel Architecture. Oxford: Oxford University Press, 2020.

; AUDRING, Jenny. Relational Morphology in the Parallel Architecture. In: Audring J. Masini F. (Eds.). The Oxford Handbook of Morphological Theory. Oxford: Oxford University Press, 2018.

JACKENDOFF, Ray; AUDRING, Jenny. Morphological schemas: theoretical and psycholinguistic issues. The Mental Lexicon. v. 11, n. 4, p. 467-493, 2016.

SALOMÃO, Maria Margarida Martins. Gramática das construções: a questão da integração entre sintaxe e léxico. Veredas, v. 6, n. 1, p. 63-74, 2009.

SCALISE, Sergio et alii. Exocentricidade na composição. Gengo Kenkyu 135, p. 49-84, 2009.

SOARES DA SILVA, Augusto. O mundo dos sentidos: Polissemia, Semântica e Cognição. Coimbra: Almedina, 2006.

TRAUGOTT, Elizabeth; TROUSDALE, G. Constructionalization and constructional changes. Oxford: Oxford University Press, 2013.

\section{Some notes on Relational morphology: a "cousin" of Construction Grammar}

Abstract: In this paper, we intend to present a recent theoretical framework that emerged in the context of Construction Grammar: the Relational Morphology. Developed in the last four years by Ray Jackendoff (USA) and Jenny Audring (Netherlands), the model innovates not only by focusing on 


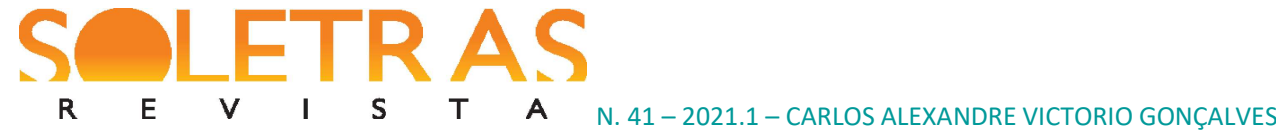

morphology, as does Booij's constructional morphology (2010), but also by emphasizing the horizontal relationships between schemes, generalization that the authors call "sister schemes". We have tried to show its advantages in the treatment of morphological issues, such as hápax suffixes and general derivational patterns, although the model also addresses syntactic issues. In the presentation this new theoretical framework, we seek to show the points of convergence and divergence between it and other constructional approaches.

Keywords: Relational Morphology. Construction Grammar. Construction Morphology. Morpholocial Schemes.

Recebido em: 20 de novembro de 2020 .

Aceito em: 20 de dezembro de 2020. 